\title{
Effect of Micronutrient Supplementation on Mood in Nursing Home Residents
}

\author{
M.A. Gosney ${ }^{a}$ M.F. Hammond ${ }^{b}$ A. Shenkinc ${ }^{c}$ S. Allsup ${ }^{d}$ \\ a Institute of Health Sciences, University of Reading, Reading, bivision of Clinical Psychology, \\ University of Liverpool, 'Department of Clinical Chemistry, Royal Liverpool University Hospital, Liverpool, \\ ${ }^{\mathrm{d}}$ Whiston Hospital, Prescot, UK
}

\section{Key Words}

Anxiety · Depression · Micronutrients · Nursing home • Selenium

\begin{abstract}
One third of older people in nursing and/or residential homes have significant symptoms of depression. In younger people, deficiencies in selenium, vitamin $C$ and folate are associated with depression. This study examines the association between micronutrient status and mood before and after supplementation. The objective was to determine whether the administration of selenium, vitamin $C$ and folate improved mood in frail elderly nursing home residents. Mood was assessed using the Hospital Anxiety and Depression rating scale (HAD), and Montgomery-Åsberg Depression Rating Scale (MADRS). Micronutrient supplementation was provided for 8 weeks in a double-blinded randomised controlled trial. Significant symptoms of depression (29\%) and anxiety (24\%) were found at baseline. $67 \%$ of patients had low serum concentrations of vitamin C, but no-one was below the reference range for selenium. Depression was significantly associated with selenium levels, but not with folate or vitamin $\mathrm{C}$ levels. No individual with a HAD depression score of $\geq 8$, had selenium levels $>1.2 \mu \mathrm{M}$. In those patients with higher HAD depression scores, there was a significant reduction in the score and a significant increase in serum selenium levels after 8 weeks of micronutrient supplementation. Placebo group scores were unchanged. This small study concluded that depression was associated with low
\end{abstract}

levels of selenium in frail older individuals. Following 8 weeks of micronutrient supplementation, there was a significant increase in selenium levels and improved symptoms of depression occurred in a subgroup.

Copyright $\odot 2008$ S. Karger AG, Basel

\section{Introduction}

Older people have a high prevalence of depression, with up to one third or more of those living in residential or nursing home, having significant symptoms [1-4]. The prevalence of depression in nursing or residential homes is at least twice that seen in the general population $[5,6]$. There are clear associations between depression and chronic illness and disability [7]. Individuals diagnosed with depression, may have poor physical and social functioning and an impaired quality of life. The presence of depression also results in increased morbidity and mortality [8-10].

Older people living in institutions tend to have a poor nutritional status. Deficiencies in zinc, selenium and vitamin $\mathrm{C}$, have been found in older hospitalised individuals $[11,12]$. In a UK study, $40 \%$ of older people living in institutions were reported to be deficient in folate, riboflavin and vitamin $C[13,14]$. Although the micronutrient status of all older people may be improved through supplementation $[15,16]$, those people who are most deficient with a relatively poor diet are found to benefit most from supplementation [17].

\section{KARGER}

Fax +4161306 1234 E-Mail karger@karger.ch www.karger.com

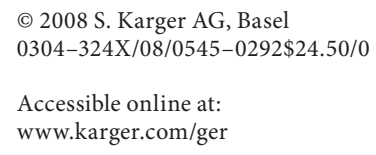

\footnotetext{
Prof. Margot Gosney

University of Reading, Institute of Health Sciences

London Road, Building 22, 1st Floor

Reading RG1 5AQ (UK)

Tel. +44 118378 6853, Fax +44 118378 6862, E-Mail m.a.gosney@reading. ac.uk
} 


\section{Micronutrients and Mood}

Vitamin and mineral supplementation can result in improved mood in younger people and in physically healthy older people [18-21]. It has been found that low folate levels are present in depressed people and supplementation, in addition to the administration of fluoxetine, significantly improved mood [22]. In addition, healthy older people with low vitamin $C$ levels and mood at baseline had improved serum levels and mood, when supplemented with oral vitamin C [23].

\section{Selenium}

Selenium is an essential trace mineral which is best known as an antioxidant. It is also part of the enzyme system necessary for the production of active thyroid hormone [24].

In some parts of the world, particularly in European countries, such as the UK, a low or diminishing selenium status may impact on general health [25].

There is increasing evidence that selenium has a protective effect against some forms of cancer, may enhance male fertility, reduce cardiovascular disease mortality and regulate some of the inflammatory mediators in asthma [26].

The relationship between mood, behaviour and cognitive function with alterations in thyroid function, has resulted in researchers suggesting that the effects of selenium status on mood, may in part be due to the complex interaction with thyroid function [27].

Patients with hypothyroidism often present with depression. In addition, thyroid function depends on selenium which is at the active centre of the iodothyronine deiodinase enzymes that catalyse the conversion of the prohormone thyroxine (T4) to the active form of thyroid hormone triiodothyronine (T3). Therefore, patients with hypothyroidism and depression may be deficient in selenium.

Chronic alcoholic patients have diminished plasma and erythrocyte, selenium and vitamin E levels, which improve towards normalisation after 14 days of alcohol abstinence [28].

Other authors have also suggested that selenium status may modify mood in patients with chronic heavy alcohol consumption. One suggested hypothesis is that mood improvement in depressed patients after a period of abstinence from alcohol might in part be due to the normalisation of selenium status [29].

Higher incidence of anxiety and depression, as well as poor overall health in patients with chronic renal failure undergoing haemodialysis, has been attributed to sele- nium deficiency and the role of selenium in depression during pregnancy and lactation has also been postulated [30].

Specific patient groups, including those undergoing long-term tube feeding may have dietary selenium deficiencies sufficient to induce ECG abnormalities [31]. The role of medications such as clozapine in reducing plasma and red cell selenium in patients with schizophrenia has been reported [32].

\section{Selenium and Cognition}

In patients with both Alzheimer type and vascular dementia, serum selenium levels were thought to have a positive protective effect on cognitive function [33] and this has been confirmed in a 9-year longitudinal study, which found cognitive decline to be associated with decreases in plasma selenium over time. In those subjects who had low plasma selenium levels, the greater the decrease in selenium, the higher the probability of cognitive decline. Akbaraly et al. [34] concluded that selenium status declined with age and may contribute to declines in neuropsychological functions in an ageing population. In a cross-sectional survey of 2,000 rural Chinese, which was unique in that $70 \%$ of the study participants had lived in the same village since birth, low selenium levels in nail samples were significantly associated with lower cognitive scores, suggesting that lifelong low selenium levels are associated with lower cognitive function [35].

\section{Selenium and Mood}

In healthy men, a diet low in selenium has no effect on mood scales; however, the lower the initial selenium status, the more the mood scores diminished, thus supporting the hypothesis that a low selenium status may result in relatively depressed mood [36]. In a study of $501 \mathrm{UK}$ subjects aged 60-74 years, who were administered different levels of selenium or placebo, supplementation increased plasma selenium levels above baseline, but did not affect mood as measured by the Profile of Moods States - Bipolar Form, or quality of life as measured by the Short Form 36 [37]. In contrast, Benton and Cook in a similar British population, found improved mood and a decrease in anxiety, using the Profile of Mood States, which correlated with the level of selenium in the diet, as estimated from a Food Frequency Questionnaire. This study, however, failed to correlate mood to serum selenium status [38, 39]. Patients with HIV/AIDS, treated with selenium therapy in a placebo-controlled doubleblinded trial, found that at 12 months the participants who had received selenium, reported increased vigour 
Table 1. Constituents of micronutrient supplement, manufacturer Recip AB, Sweden

\begin{tabular}{lc}
\hline Vitamin $\mathrm{A}, \mathrm{IU}$ & 2,666 \\
Vitamin $\mathrm{D}_{3}, \mathrm{IU}$ & 400 \\
Vitamin $\mathrm{E}, \mathrm{mg}$ & 60 \\
Vitamin $\mathrm{B}_{1}, \mathrm{mg}$ & 1.2 \\
Vitamin $\mathrm{B}_{2}, \mathrm{mg}$ & 1.4 \\
Vitamin $\mathrm{B}_{6}, \mathrm{mg}$ & 3.0 \\
Nicotinamide, mg & 14 \\
Folic acid, mg & 0.6 \\
Vitamin $\mathrm{B}_{12}, \mu \mathrm{g}$ & 200 \\
Biotin, $\mu \mathrm{g}$ & 30 \\
Calcium pantothenate, mg & 5 \\
Vitamin $\mathrm{C}, \mathrm{mg}$ & 120 \\
Iron, mg & 12 \\
Zinc, mg & 14 \\
Copper, mg & 2 \\
Iodine, $\mu \mathrm{g}$ & 150 \\
Manganese, mg & 1 \\
Chromium, $\mu \mathrm{g}$ & 50 \\
Selenium, $\mu \mathrm{g}$ & 60 \\
Molybdenum, $\mu \mathrm{g}$ & 100 \\
Calcium, mg & 240 \\
Magnesium, mg & 100 \\
\hline
\end{tabular}

and less anxiety, compared to the placebo-treated individuals, although there was no apparent effect of selenium on either distress or depression [40].

\section{Aim}

The aim of this study was to examine the association between micronutrients (specifically selenium, folate and vitamin $\mathrm{C}$ ), and symptoms of depression and anxiety in a sample of frail older individuals living in nursing and residential homes. We hypothesised that lower levels of each of the micronutrients would correlate with greater symptoms of both anxiety and depression, and that those individuals receiving micronutrient supplementation would have improved mood and reduced anxiety compared with the placebo-treated group.

\section{Methods}

\section{Subjects}

Seventy-three residents from eleven nursing and residential homes on Merseyside participated in this study. All individuals approached were aged over 60 years and were able to give informed consent (abbreviated mental test score of 7 or above and not critically ill). The study was approved by the local Research and Ethics Committee and all participants gave written informed consent.
All subjects had normal thyroid function tests and none were receiving either thyroxine supplementation, or pharmacological treatment for a depressive illness up to 2 weeks before, during or within the assessment period.

\section{Mood Ratings}

Baseline mood ratings were completed during the 2 weeks prior to the commencement of micronutrient/placebo supplements. A 2-week period was chosen to ensure that all participants started the study at the same time and that mood assessment could be completed on all of them within this period. Endpoint ratings were completed within 2 weeks of finishing supplementation. All intervals between baseline and endpoint ratings were $8-10$ weeks apart. The measurements included:

(1) The Montgomery-Åsberg Depression Rating Scale (MADRS) which is a continuous measure of severity of depressive symptoms. This scale has been shown to be reliable and valid in elderly and frail populations. A score of $\geq 18$ has both a high specificity and positive predictive value of the diagnosis of depression in frail older people.

(2) The Hospital Anxiety and Depression Scale (HAD). This consists of two 7-item scales designed to screen physically ill populations, for both anxiety and depression. It has been validated in older people. On each scale, a score below 8 is considered to be normal, scores of $8-10$ being borderline and scores $\geq 11$ indicative of the presence of anxiety and/or depression.

We chose both HAD and MADRS, because the former measures positive affect, whereas the latter measures negative affect. Both scales have been validated in older people, particularly amongst frail individuals. Both scales were scored during face to face interviews to ensure that participants with visual and physical impairments were not excluded, in an attempt to improve the validity of the data obtained. No further scales were included as this population was frail and unlikely to be able to complete more than 2 scales.

\section{Biochemistry}

Twenty millilitres of venous blood was collected and separated in a validated laboratory within $2 \mathrm{~h}$ of collection. Serum selenium was measured using inductively coupled mass spectrometry, folate by immunoassay and vitamin $\mathrm{C}$ by a colorimetric assay.

\section{Intervention}

All participants were randomly assigned to receive either placebo or active micronutrient supplementation in a one to one ratio, using random numbers generated by the Hospital Pharmacy Trials Unit. The micronutrient supplement and placebo were supplied by Recip AB Sweden and were identical in appearance. Participants took two tablets, twice a day for 8 weeks, administered by nursing home staff. Compliance was verified during the trial by tablet counting at two weekly intervals by a researcher blinded to the intervention. The constituents of the active supplement are listed in table 1.

\section{Statistical Analysis}

Due to the ordinal nature of the mood ratings, non-parametric tests (Spearman's rho and Wilcoxon signed-ranks test) were used to examine the association between mood measures and individual's micronutrients status and any change in mood scores between measurements at baseline and endpoint. 
Student's t tests were used to test for significant differences in micronutrients between groups at baseline and paired t tests for changes in micronutrient measures between baseline and endpoint. Significance levels of 0.01 (one tailed) were considered to be statistically significant. All analyses were performed using SPSS.

\section{Results}

Seventy-three participants commenced the study, of whom 59 completed the assessments. The median age was 82 years.

\section{Mood at Baseline}

HAD depression scores of 8 or more were found in $29 \%$ of participants. $22.5 \%$ scored 8 or more on the HAD anxiety scale. Of these 7 (9.6\%) had anxiety and depression scores of $\geq 11$, suggesting serious psychological distress. Seventeen subjects (23\%) had MADRS scores $\geq 18$ (table 2).

\section{Micronutrient Status}

At baseline, only one person was deficient in folate (i.e. $<1.5 \mu \mathrm{g} / \mathrm{l}$ ) and no-one had a serum selenium level of $<0.7 \mu \mathrm{M}$. However, $49(67 \%)$ of residents had vitamin $\mathrm{C}$ levels $<23 \mu \mathrm{M}$ (table 3 ).

\section{Relationship between Mood and Micronutrient Status}

There were statistically significant negative relationships between serum selenium and both depression measures. There was also a trend towards a significant negative relationship between selenium and anxiety scores (table 4). All 18 participants with depression scores $\geq 8$ on the HAD depression scale had selenium levels $<1.2$ $\mu \mathrm{M}$. No significant correlations were noted between folate and/or vitamin $\mathrm{C}$, depression and/or anxiety measures.

\section{Effect of Supplementation}

Fifty-nine participants had complete baseline and endpoint measurements of mood. At 8 weeks, no participant had a folate or selenium level below the reference range and only one participant $(2 \%)$ had a vitamin $\mathrm{Clev}$ el below the reference range (table 3 ). At baseline prior to either supplementation or placebo, there were no statistically significant differences on any of the mood measures. A total of 33 out of 37 participants in the placebo group had complete baseline and endpoint measures and 26 of 36 active treatment participants also had complete sets of measures. There were no statistically significant differences between the baseline scores for those completing the study, compared with the total sample in either the placebo or the active group (table 5).

There was a trend towards a significant reduction in HAD depression scores (i.e. an increase in positive affect) in the active treatment group (Wilcoxon test $\mathrm{Z}=-1.48$, $\mathrm{p}=0.07)$ and no significant change in the placebo group $(Z=-0.84, p=0.20)$. In the HAD anxiety scores there was a trend towards a significant reduction in the placebo group $(Z=-1.57, \mathrm{p}=0.06)$, but not in the active treatment

Table 2. HADS and MADRS scores at baseline

\begin{tabular}{lccc}
\hline & \multicolumn{2}{l}{ HADS } & \multirow{2}{*}{ MADRS } \\
\cline { 2 - 3 } & anxiety & depression & \\
\hline Subjects & 73 & 73 & 72 \\
Mean score \pm SD & $5.4 \pm 4.8$ & $4.84 \pm 4.1$ & $9.2 \pm 8.6$ \\
Median score & 4.0 & 3.5 & 6.0 \\
Score range & $0-18$ & $0-14$ & $0-29$ \\
$0-7$ ('normal') & $77.5 \%(55)$ & $71 \%(52)$ & \\
$8-10$ ('borderline') & $8 \%(7)$ & $16 \%(11)$ & \\
$\geq 11$ ('depressed') & $14.5 \%(11)$ & $13 \%(10)$ & \\
$\geq 18$ ('depressed') & & & $22 \%(16)$ \\
\hline
\end{tabular}

Table 3. Serum data at baseline and 8 weeks

\begin{tabular}{|c|c|c|c|c|c|c|}
\hline & \multirow{2}{*}{$\begin{array}{l}\text { Reference } \\
\text { range }\end{array}$} & \multirow{2}{*}{$\begin{array}{l}\text { Baseline } \\
\text { mean }\end{array}$} & \multirow{2}{*}{$\begin{array}{l}8 \text { weeks } \\
\text { mean }\end{array}$} & \multirow{2}{*}{$\begin{array}{l}\text { Baseline } \\
\text { range }\end{array}$} & \multicolumn{2}{|c|}{ Participants below reference range, $\%$} \\
\hline & & & & & at baseline & at 8 weeks \\
\hline Folate, $\mu \mathrm{g} / \mathrm{l}$ & $1.5-10$ & 5.88 & 12.0 & $0.9-39.8$ & 1.6 & 0 \\
\hline Vitamin $C, \mu M$ & $23-118$ & 20.15 & 64.1 & $1-75$ & 67.0 & 1.8 \\
\hline Selenium, $\mu \mathrm{M}$ & $0.7-1.6$ & 1.03 & 1.1 & $1-2$ & 0 & 0 \\
\hline
\end{tabular}

Reference ranges for micronutrients and micronutrient status of participants at baseline. 
group $(\mathrm{Z}=-0.18, \mathrm{p}=0.43)$. There was no significant change in either active or placebo group in the MADRS scores (active: $\mathrm{Z}=0.34, \mathrm{p}=0.36$; placebo: $\mathrm{Z}=0.25, \mathrm{p}=$ $0.25)$.

\section{Effect of Supplementation in Individuals with} High Depression Scores

At baseline, there were 8 people in the placebo group and 10 in the active treatment group with HAD depression scores in the abnormal range $(\geq 8)$ who subsequently completed the study. Among those with abnormal HAD depression scores at baseline, those in the active treatment group showed a significant increase in seleni-

Table 4. Association between measures of mood and biochemical parameters

\begin{tabular}{lrrr}
\hline $\begin{array}{l}\text { Micro- } \\
\text { nutrient }\end{array}$ & \multicolumn{1}{l}{ HADS } & \multirow{2}{*}{ MADRS } \\
\cline { 2 - 3 } & anxiety & depression & \\
\hline Selenium & $-0.293(0.011)$ & $-0.341(0.004)$ & $-0.358(0.003)$ \\
Folate & $0.078(0.163)$ & $0.014(0.458)$ & $-0.017(0.450)$ \\
Vitamin C & $-0.146(0.132)$ & $-0.157(0.113)$ & $-0.204(0.06)$ \\
\hline
\end{tabular}

um levels (paired $t$ test -2.94 , d.f. 9; one-tailed significance 0.009 ) and a significant decrease in depression scores (Wilcoxon signed ranks test $\mathrm{Z}=-2.15$; one-tailed significance 0.016 ) after 8 weeks. However, in the placebo group, selenium levels were unchanged (paired t test $\mathrm{t}=$ -0.24 , d.f. $6, p=0.41$ ) and HAD depression scores did not show significant change (Wilcoxon $\mathrm{Z}=-1.02$, one-tailed significance 0.15 ).

Among those people with abnormal MADRS scores $(\geq 18)$ at baseline, there were no significant change in MADRS scores in either group (active: $Z=-1.19$, onetailed significance 0.12 ; placebo: $Z=-1.21$, one-tailed significance 0.11).

\section{Discussion}

Mood and Nursing in Residential Home Residents

One quarter of all participants scored in the abnormal range of the anxiety scale of the HAD and almost one third scored in the abnormal range of the depression scale of HAD. 21.7\% had significantly high levels of negative affect as indicated by MADRS scores of $\geq 18$. This prevalence level of depression is similar to that seen in other populations of older people in institutions [1-4].

Table 5. Mood data

\begin{tabular}{|c|c|c|c|c|}
\hline & \multicolumn{2}{|c|}{ Placebo $(\mathrm{n}=33)$} & \multicolumn{2}{|c|}{ Active $(n=26)$} \\
\hline & baseline & endpoint & baseline & endpoint \\
\hline \multicolumn{5}{|c|}{ HADS anxiety score } \\
\hline Mean $\pm S D$ & $4.97 \pm 4.69$ & $4.12 \pm 4.1$ & $6.85 \pm 5.16$ & $6.65 \pm 5.03$ \\
\hline Median & 4.0 & 3.0 & 5.5 & 6.0 \\
\hline Range & $0-17$ & $0-16$ & $0-18$ & $0-18$ \\
\hline $\mathrm{N}$ scores $0-7$ & $26(79)$ & $27(82)$ & $18(69)$ & $17(65)$ \\
\hline $\mathrm{N}$ scores $8-10$ & $3(9)$ & $2(6)$ & $2(8)$ & $4(16)$ \\
\hline $\mathrm{N}$ scores $\geq 11$ & $4(12)$ & $4(12)$ & $6(23)$ & $5(19)$ \\
\hline \multicolumn{5}{|c|}{ HADS depression score } \\
\hline Mean $\pm S D$ & $4.55 \pm 4.68$ & $4.88 \pm 3.81$ & $6.12 \pm 3.81$ & $5.19 \pm 3.71$ \\
\hline Median & 3.0 & 4.0 & 5.0 & 5.0 \\
\hline Range & $0-18$ & $0-13$ & $1-13$ & $0-13$ \\
\hline $\mathrm{N}$ scores $0-7$ & $25(76)$ & $24(73)$ & $16(62)$ & $20(77)$ \\
\hline $\mathrm{N}$ scores $8-10$ & $4(12)$ & $7(21)$ & $5(19)$ & $3(11.5)$ \\
\hline $\mathrm{N}$ scores $\geq 11$ & $4(12)$ & $2(6)$ & $5(19)$ & $3(11.5)$ \\
\hline \multicolumn{5}{|l|}{ MADRS score } \\
\hline Mean $\pm S D$ & $8.76 \pm 8.78$ & $7.91 \pm 7.69$ & $10.42 \pm 9.88$ & $10.5 \pm 8.6$ \\
\hline Median & 5.0 & 5.0 & 6.5 & 8.0 \\
\hline Range & $0-31$ & $0-26$ & $0-29$ & $0-27$ \\
\hline
\end{tabular}

Figures in parentheses indicate percentages. 
Prevalence of anxiety symptoms is, however, also high and this has not been previously noted. There is, however, some evidence on the prevalence of anxiety diagnosed using the Geriatric Mental State Schedule in certain older populations. In chronic obstructive pulmonary disease, $18 \%$ of patients were found to have anxiety, and this was a major predictor of hospital admission [41].

\section{Mood and Micronutrient Status}

Despite previous research suggesting an association between folate or vitamin C levels and low mood, our data demonstrated no such relationship. We did however find a highly significant negative association between symptoms of depression and selenium levels, although the serum selenium levels were apparently within the normal range. None of our sample group had a serum selenium level below the minimum accepted reference range. However, we know that the nutritional intake of selenium in the UK is equivalent to a low selenium diet [42]. Although it is difficult to speculate about selenium intake in a frail older nursing and residential home population, it is known that low serum selenium regardless of intake is directly associated with greater age, poor health and general frailty among older people [43]. Nonetheless, the observation that improvement of selenium status was associated with improvement in depression score suggests that serum selenium is an insensitive marker of selenium status in nervous tissue. The supplementation of older people with selenium has resulted in reduced plasma thyroxine (T4), suggesting improved conversion to the active thyroid hormone T3 [44]. Whilst our patients had normal thyroid function at baseline, we did not assess any alteration that may have occurred during selenium supplementation. It is therefore difficult to dismiss Sher's hypothesis that 'the effect of selenium deprivation on mood ... might therefore be partly mediated by changes induced by selenium deficiency in thyroid function' [45].

\section{Effect of Micronutrient Supplementation on Mood}

After 8 weeks of active supplementation, there was a trend towards a significant increase in positive affect, i.e. a reduction in HAD depression scores and statistically significant improvement in HAD depression scores among those people who were depressed at baseline and had an associated significant improvement in serum selenium levels. This effect was not reflected in the MADRS scores. There was no reduction in anxiety scores within HAD, despite the apparent comorbidity of anxiety and depression in the sample. The MADRS, as well as the HAD anxiety items tend to assess negative affect whereas the depression score on the HAD depression scale reflects an absence of positive affect or anhedonic state, which is a presentation of depression, more typically seen among older people [46].

Whilst it is possible that a longer duration of study may have shown further alterations in mood or a positive association with other micronutrients, a time period of 8 weeks was chosen to ensure that morbidity and mortality in this frail population did not significantly decrease numbers. Seasonal variability also impacts on mood and therefore the research needed to be carried out in the same season. Other studies where mood has been affected by micronutrients have also had durations of 4-8 weeks.

The most important findings from this study were the association of low positive affect with relatively low levels of selenium and the significant improvements in mood after 8 weeks of active supplementation with a measurable increase in serum selenium. Whether this trend towards improvement in HAD depression scores in the supplemented group was due to the improvement in selenium levels, can only be speculated.

\section{Study Limitations}

There was an unsystematic loss of subjects at endpoints from the active treatment group. Return visits to two of the homes were impossible and there was, as is often found in studies of older frail individuals, a number of subjects unable to complete studies due to acute illness or increase in frailty. Those who completed the treatment in the active treatment group were apparently more depressed and anxious than those in the placebo group, although the differences were not statistically significant.

\section{Conclusions}

Our study shows a high level of psychiatric morbidity within residential and nursing home residents. It suggests that selenium may be particularly implicated in improvement of mood in frail older people. Further research in a longitudinal placebo controlled study looking at individual substances, such as selenium, thiamine and zinc, as well as a specific study of selenium administration and its effects on serum thyroxine should be conducted. If depression is as common in nursing home residents as suggested, particularly when using the HAD 
depression score, it is likely that some individuals would benefit from anti-depressant therapy. There is no evidence whether micronutrient coadministration with antidepressants may act in a synergistic fashion and therefore the role of micronutrient coadministration with antidepressants requires further research. Whilst depres- sion and dementia in nursing home residents is well documented and researched, prevalence of anxiety found in our sample suggests that further research in the diagnosis and potential management of this condition is required.

\section{References}

1 Phillips CJ, Henderson AS: The prevalence of depression among Australian nursing home residents: results using draft ICD-10 and DSM-III-R criteria. Psychol Med 1991; 21:739-748

-2 Burrows AB, Satlin A, Salzman C, Nobel K, Lipsitz LA: Depression in a long-term care facility: clinical features and discordance between nursing assessment and patient interviews. J Am Geriatr Soc 1995;43:1118-1122.

-3 Mann AH, Schneider J, Mozley CG, Levin E, Blizard R, Netten A, Kharicha K, Egelstaff R, Abbey A, Todd C: Depression and the response of residential homes to physical health needs. Int J Geriatr Psychiatry 2000; 15:1105-1112.

4 Teresi J, Abrams R, Holmes D, Ramirez M, Eimicke J: Prevalence of depression and depression recognition in nursing homes. Soc Psychiatry Psychiatr Epidemiol 2001;36: 613-620.

5 Beekman AT, Copeland JR, Prince MJ: Review of community prevalence of depression in later life. Br J Psychiatry 1999;174:307311.

6 Djernes JK: Prevalence and predictors of depression in populations of elderly: a review. Acta Psychiatr Scand 2006;113:372-387.

$\checkmark 7$ Watson LC, Lehmann S, Mayer L, Samus Q, Baker A, Brandt J, Steele C, Rabins P, Rosenblatt A, Lyketsos C: Depression in assisted living is common and related to physical burden. Am J Geriatr Psychiatry 2006;14: 876-883.

$\checkmark 8$ Beekman AT, Kriegsman DM, Deeg DJ, van Tilburg W: The association of physical health and depressive symptoms in the older population: age and sex differences. Soc Psychiatry Psychiatr Epidemiol 1995:30:32-38.

$\checkmark 9$ Geerlings SW, Beekman AT, Deeg DJ, Van Tilburg W: Physical health and the onset and persistence of depression in older adults: an eight-wave prospective community-based study. Psychol Med 2000;30:369-380.

10 Watson LC, Garrett JM, Sloane PD, GruberBaldini AL, Zimmerman S: Depression in assisted living: results from a four-state study. Am J Geriatr Psychiatry 2003;11:534542 .

-11 Mandal SK, Ray AK: Vitamin C status of elderly patients on admission into an assessment geriatric ward. J Int Med Res 1987;15: 96-98.
12 Girodon F, Lombard M, Galan P, BrunetLecomte P, Monget AL, Arnaud J, Preziosi P, Hercberg S: Effect of micronutrient supplementation on infection in institutionalized elderly subjects: a controlled trial. Ann Nutr Metab 1997;41:98-107.

13 Bates CJ, Prentice A, Cole TJ, van der Pols JC, Doyle W, Finch S, Smithers G, Clarke PC: Micronutrients: highlights and research challenges from the 1994-1995 National Diet and Nutrition Survey of people aged 65 years and over. Br J Nutr 1999;82:7-15.

14 Bates CJ, Prentice A, Finch S: Gender differences in food and nutrient intakes and status indices from the National Diet and Nutrition Survey of people aged 65 years and over. Eur J Clin Nutr 1999;53:694-699.

15 van der Wielen RP, van Heereveld HA, de Groot CP, van Staveren WA: Nutritional status of elderly female nursing home residents; the effect of supplementation with a physiological dose of water-soluble vitamins. Eur Clin Nutr 1995;49:665-674.

16 Wouters-Wesseling W, Wouters AE, Kleijer CN, Bindels JG, de Groot CP, van Staveren WA: Study of the effect of a liquid nutrition supplement on the nutritional status of psycho-geriatric nursing home patients. Eur J Clin Nutr 2002;56:245-251.

17 Ussher JM, Swann C: A double blind placebo controlled trial examining the relationship between Health-Related Quality of Life and dietary supplements. Br J Health Psychol 2000;5:173-187.

18 Benton D, Donohoe RT: The effects of nutrients on mood. Public Health Nutr 1999;2: 403-409.

19 Benton D: Carbohydrate ingestion, blood glucose and mood. Neurosci Biobehav Rev 2002;26:293-308.

20 Benton D, Nabb S: Carbohydrate, memory, and mood. Nutr Rev 2003;61:S61-S67.

-21 Carroll D, Ring C, Suter M, Willemsen G: The effects of an oral multivitamin combination with calcium, magnesium, and zinc on psychological well-being in healthy young male volunteers: a double-blind placebocontrolled trial. Psychopharmacology (Berl) 2000;150:220-225.
22 Coppen A, Bailey J: Enhancement of the antidepressant action of fluoxetine by folic acid: a randomised, placebo controlled trial. J Affect Disord 2000;60:121-130.

-23 Smith A, Clark R, Nutt D, Haller J, Hayward S, Perry K: Anti-oxidant vitamins and mental performance of the elderly. Hum Psychopharmacol 1999;14:459-471.

24 Rayman MP: The importance of selenium to human health. Lancet 2000;356:233-241.

25 Rayman MP, Rayman MP: The argument for increasing selenium intake. Proc Nutr Soc 2002;61:203-215.

26 Brown KM, Arthur JR: Selenium, selenoproteins and human health: a review. Public Health Nutr 2001;4:593-599.

27 Sher L: Role of thyroid hormones in the effects of selenium on mood, behavior, and cognitive function. Med Hypotheses 2001; 57:480-483.

28 Girre C, Hispard E, Therond P, Guedj S, Bourdon R, Dally S: Effect of abstinence from alcohol on the depression of glutathione peroxidase activity and selenium and vitamin E levels in chronic alcoholic patients. Alcohol Clin Exp Res 1990;14:909-912.

29 Sher L: Role of selenium depletion in the etiopathogenesis of depression in patients with alcoholism. Med Hypotheses 2002;59: 330-333.

30 Bodnar LM, Wisner KL: Nutrition and depression: implications for improving mental health among childbearing-aged women. Biol Psychiatry 2005;58:679-685.

-31 Paku S, Inaba Y, Seki C, Hara Y, Yamazaki M, Tsukada M: Selenium deficiency and electrocardiography changes in patients with severe motor and intellectual disabilities on long-term tube feeding (in Japanese). No To Hattatsu 2002;34:37-42.

32 Vaddadi KS, Soosai E, Vaddadi G: Low blood selenium concentrations in schizophrenic patients on clozapine. Br J Clin Pharmacol 2003;55:307-309.

33 Smorgon C, Mari E, Atti AR, Dalla Nora E, Zamboni PF, Calzoni F, Passaro A, Fellin R: Trace elements and cognitive impairment: an elderly cohort study. Arch Gerontol Geriatr Suppl 2004;(9):393-402.

>34 Akbaraly NT, Hininger-Favier I, Carriere I, Arnaud J, Gourlet V, Roussel AM, Berr C: Plasma selenium over time and cognitive decline in the elderly. Epidemiology 2007;18: 52-58. 
-35 Gao S, Jin Y, Hall KS, Liang C, Unverzagt FW, Ji R, Murrell JR, Cao J, Shen J, Ma F, Matesan J, Ying B, Cheng Y, Bian J, Li P, Hendrie HC: Selenium level and cognitive function in rural elderly Chinese. Am J Epidemiol 2007; 165:955-965.

>36 Hawkes WC, Hornboste L: Effects of dietary selenium on mood in healthy men living in a metabolic research unit. Biol Psychiatry 1996;39:121-128.

>37 Rayman M, Thompson A, Warren-Perry M, Galassini R, Catterick J, Hall E, Lawrence D, Bliss J: Impact of selenium on mood and quality of life: a randomized, controlled trial. Biol Psychiatry 2006;59:147-154.

$\checkmark 38$ Benton D, Cook R: Selenium supplementation improves mood in a double-blind crossover trial. Psychopharmacology (Berl) 1990; 102:549-550.

39 Benton D, Cook R: The impact of selenium supplementation on mood. Biol Psychiatry 1991;29:1092-1098.
40 Shor-Posner G, Lecusay R, Miguez MJ, Moreno-Black G, Zhang G, Rodriguez N, Burbano X, Baum M, Wilkie F: Psychological burden in the era of HAART: impact of selenium therapy. Int J Psychiatry Med 2003; 33:55-69.

41 Yohannes AM, Baldwin RC, Connolly MJ: Depression and anxiety in elderly outpatients with chronic obstructive pulmonary disease: prevalence, and validation of the BASDEC screening questionnaire. Int J Geriatr Psychiatry 2000;15:1090-1096.

42 MAFF: Food Surveillance Information Sheet No 126. London, Joint Food Safety and Standards Information Group, UK Ministry of Agriculture, Fisheries and Food, 1997.

43 Bates CJ, Thane CW, Prentice A, Delves HT: Selenium status and its correlates in a British national diet and nutrition survey: people aged 65 years and over. J Trace Elem Med Biol 2002;16:1-8.
44 Olivieri O, Girelli D, Azzini M, Stanzial AM, Russo C, Ferroni M, Corrocher R: Low selenium status in the elderly influences thyroid hormones. Clin Sci (Lond) 1995;89:637642 .

45 Sher L: Selenium and human health. Lancet 2000;356:943.

46 Lawton MP, Parmelee PA, Katz IR, Nesselroade J: Affective states in normal and depressed older people. J Gerontol B Psychol Sci Soc Sci 1996;51:309-316.

47 Benton D, Griffiths R, Haller J: Thiamine supplementation mood and cognitive functioning. Psychopharmacology (Berl) 1997; 129:66-71.

48 Smidt LJ, Cremin FM, Grivetti LE, Clifford AJ: Influence of thiamin supplementation on the health and general well-being of an elderly Irish population with marginal thiamin deficiency. J Gerontol 1991;46:16-22. 